\title{
Cochlear implantation and electro-acoustic stimulation: Current status and developments
}

\author{
Akif Gunes, Elif Karali
}

Department of Otorhinolaryngology, Bolu Abant Izzet Baysal University, Faculty of Medicine, Bolu, Turkey

\section{ABSTRACT}

The number of people with hearing loss constitutes approximately $6.5 \%$ of the world population. Hearing loss leads to alienation from social environments and deterioration in quality of life in adults. Children with hearing loss, on the other hand, have lower literacy and lower educational attainments. There are auditory prostheses, called cochlear implant (CI) devices, which are designed using a special speech coding strategy to convert acoustic information into electrical stimulation for patients with inadequate traditional hearing aids used for rehabilitation of hearing loss. These devices are surgically implanted and cause direct stimulation of primary afferent neurons in the inner ear. The auditory nerve is stimulated by the electrodes placed on the cochlea, and thus the auditory message can be sent up to the auditory cortex. With CI, increases in speaking, language and comprehension skills can be achieved.

Key words: Hearing loss, cochlear implant, cochlea, electro-acoustic stimulation.

$\triangle$ Akif Gunes, M.D., Associate Prof.

Department of Otorhinolaryngology, Bolu Abant Izzet Baysal University, Faculty of Medicine, Bolu, Turkey

E-mail: akif_gunes@hotmail.com

Received: 2021-10-07

Accepted: 2021-10-26/Published online: 2021-11-01

\section{Introduction}

The number of people with hearing loss constitutes approximately $6.5 \%$ of the world population [1]. The World Health Organization estimated this rate as $0.8 \%$ for high-income countries [2]. The level of hearing loss, which is characterized as a decrease in the meaning and perception of sounds, is determined by a pure tone audiogram. Hearing thresholds are measured in decibels $(\mathrm{dB})$ and are classified as mild (25-40 dB), moderate $(40 \quad 55 \mathrm{~dB})$, moderate (55-70 dB), severe (70-90 dB), and severe (> $90 \mathrm{~dB}$ ) hearing loss classified [3]. According to the World Health Organization, it has been stated that when hearing loss is $>40$ $\mathrm{dB}$ in adults and $>30 \mathrm{~dB}$ in children, there will be loss of function in people [4]. Severe hearing loss, which may occur before the age of three, seriously affects language development negatively [5]. The literacy level and education level of children with severe hearing loss also decrease seriously [6, 7]. It negatively affects their quality of life, learning and development in terms of school activities and social interactions [8]. Hearing loss in adults is also associated with low income and associated economic difficulties and poor quality of life [9-11].

Conventional hearing aids are the primary tool for auditory rehabilitation in patients with sensorineural hearing loss (SNHL). Inadequate amplification with conventional hearing aids and limitations about with these aids such as acoustic feedback, spectral distortion, 
nonlinear/harmonic distortion, external ear canal occlusion, lack of view/visibility, orientation, and social stigma of hearing aid use, have led to the development of implantable hearing aids [12].

Cochlear implants (CI) are auditory prostheses that convert acoustic information into electrical stimulation. Bipolar spiral ganglion neurons and primary afferent cells are used by CI without intermediary for electrical stimulation. CI follows a mechanism based on the principle of stimulation of the cochlea by means of electrodes placed up to the modiolus, and the direct stimulation of primary neurons by bypassing the electrical stimulation of the outer ear, middle ear and hair cells [12]. In short, electrical impulses bypass dysfunctional hair cells and directly depolarize primary afferent neurons [12].

Historical development of devices, devices and the principle of operation of devices

The first documented electrical stimulation of the auditory system occurred in 1790 [13, 14]. In addition, alternating currents, various charges, polarities and densities have been tried in various studies [15, 16]. In 1930, it was shown that electrical signals coming from the cat cochlea and very similar to waveforms can be copied and generated [16, 17].

An electrode combined with a receiver coil was implanted in a patient who had a distal cochlear nerve resection in 1957, and it was shown that the device could be stimulated with an external coil for several months. This stimulation enabled the patient to recognize sound awareness and simple words [14]. At the beginning of the 1960s, experiments were started by placing simple wires, wires with ball electrodes, and even simple strings in the scale tympani $[15,18]$. In the light of these studies, implantable hearing aids began to be developed in 1972. In this way, the first clinical trials were started in 1973 [13, 18]. The validity of direct electrical stimulation of auditory nerve fibers (electroacoustic stimulation) as a rehabilitation strategy was accepted in 1977 [14, 19]. After single-channel implanted devices, multichannel CI devices with open-set word recognition started to be developed [14, 20, 21]. Today, there are various devices produced by three different companies (Cochlear Corporation, Med-El, Advanced Bionics) with different electrode numbers and lengths [12, 22].

All CI systems consist of two main parts, an outer part containing a microphone, sound processor and transmission system, and an inner part containing the receiver/stimulator and electrode array. Generally, an external microphone picks up ambient sound and speech and sends the information to a body-worn or ear-level type sound processor. The speech processor converts the sounds into electrical signals sent over the skin or to the internal receiver/stimulus via radio frequency transmission. Transmission of the signal occurs when the external magnet in the transmitter is successfully aligned with the internal magnet in the receiver/stimulator. The receiver/exciter part decodes the signals and transmits them to electrodes located in the cochlea. Nerve stimulation occurs thanks to the electrodes and this stimulation is transmitted to the auditory center in the cortex [12].

\section{Patient selection}

In addition to a complete physical examination, a detailed otolaryngology and head and neck examination should be performed. However, the first step in patient selection is an audiological evaluation, and the level of hearing loss must be evaluated. After the evaluation of candidates for CI, imaging 
methods (computed tomography and magnetic resonance imaging) should definitely be used [22].

When the adult selection criteria in the latest clinical studies for cochlear implantation are evaluated, firstly, a pure tone average (PTA) hearing level of $70 \mathrm{~dB}$ or higher, secondly, at least three months of appropriate hearing aid use or adequate amplification, and thirdly, discrimination scores, namely speech comprehension scores are less than 50\%, fourthly, the central auditory pathways and cochlear nerve are complete in the evaluations, and finally, there are no contraindications to surgery [12].

Comprehensive audiometric assessment with air and bone conduction thresholds between 250 and $8000 \mathrm{~Hz}$, along with speech discrimination scores, is essential for initial assessments [22].

Considering the candidate evaluation criteria for $\mathrm{CI}$ in the childhood age group; It can be done in any age group from 12 months to 17 years old. Deep SNHL (PTA thresholds $\geq 90 \mathrm{~dB}$ $\mathrm{HL})$; is the absence of developmentally appropriate auditory capacity, defined as $20 \%$ to less than $30 \%$ on monosyllabic word tests, with minimal benefit from hearing aids and measured using parent-reported scales for younger children. Other criteria are defined as the completeness of the central auditory pathways and the cochlear nerve and the absence of any contraindication to surgery. In addition, having a hearing aid for at least 3 to 6 months before CI surgery, realistic expectations of family members, and enrollment in a postoperative rehabilitation program that supports the development of auditory skills are also important criteria [12].

It is difficult to determine the degree of hearing loss in infants and children with PTA evaluation. Also, applying speech audiometry is not easy in these age groups. For this reason, behavioral audiometry is more prominent for evaluation purposes in these age groups. Initial hearing loss must be confirmed by auditory brainstem responses (ABR) and otoacoustic emission (OAE) [22, 23].

Language and intelligence assessments are also important, especially in the pediatric population, as the ultimate goal of cochlear implantation is effective communication. A psychological assessment is performed to assess the child's verbal and nonverbal intelligence, attention and memory skills, and visual-motor integration. It is also important to know the cognitive abilities of the child when considering a child for CI, pre-counseling the family and planning possible rehabilitation needs later [24].

\section{Bilateral cochlear implantation applications}

In the pediatric age group, unilateral CI practice provides significant benefits for speech recognition in a quiet environment and meets a person's basic auditory needs. However, in patients with bilateral hearing loss who underwent unilateral CI, difficulties may be experienced in ambient noise and multiple sound environments. More difficulties may be seen in perceiving the direction of the sound [25]. Hearing with two ears is always much more effective than hearing with one ear, considering the shadow effect of the head, the gathering effect of binaural sound, and the effect of silencing binaural noise [26, 27]. The ability to form new neural connections in the brain is greatest in the first 3.5 years [28]. Therefore, it is critical for auditory development and language acquisition in the early stages of life [28]. Early CI in early detected hearing loss may prevent permanent changes in the auditory cortex [29]. While unilateral CI contributes to the development of 
the auditory pathways and auditory cortex on the operated side, maturation cannot occur on the non-implanted side [28, 30]. Another issue is that, unlike sequential bilateral CI at different times, simultaneous bilateral $\mathrm{CI}$ is more effective and it should be known that the gains can be higher [31].

Bilateral CI is also significantly beneficial in the adult age group [25]. Bilateral CI applications are more beneficial in people with meningitis, acute bilateral profound hearing loss, and vision problems in addition to hearing loss. Bilateral CI may improve the auditory function of these patients. However, bilateral CI applications are applied less frequently in the adult age group than in the pediatric age group [28].

The group that can benefit more from bilateral $\mathrm{CI}$ in the adult age group and is applied more is the young adult group. Significant auditory support and improved sound localization for better hearing in noisy environments in these age groups can provide significant advantages for education and employment opportunities [29].

\section{Gains after cochlear implant surgery}

In the postoperative period, patients in the adult age group have a more advanced voice perception ability compared to the preoperative period. This perception is particularly pronounced at higher frequencies. Sound detection thresholds are approximately 25 to 30 $\mathrm{dB} \mathrm{HL}$ in the range of 250 to $4000 \mathrm{~Hz}$ postoperatively [32]. Adult patients who develop post-lingual hearing loss after language development generally have a significant increase in speech perception levels after the first month postoperatively. In patients with pre-lingual hearing loss before language development is completed, the gains are lower compared to the post-lingual group. However, even pre-lingually, there can be significant improvements in speech perception after CI [12].

Auditory gains of approximately $25 \mathrm{~dB} \mathrm{HL}$ for frequencies of 250 to $4000 \mathrm{~Hz}$ for adults in the postoperative period are also valid for the pediatric age group. These levels are important for the development of auditory skills and communication. Studies with children show that earlier CI is necessary for high performance [12]. It should also be known that postoperative performance and speechperception skills are adversely affected in patients with a short period of hearing aid use before CI [12]. It is also known that there is a steady increase in language and speech performance for 3 to 5 years in the postoperative period. Determination of suitable candidates before the surgery and the rehabilitation program applied after the surgery have a great impact on the success of cochlear implantation. Different evaluation and followup processes are applied in pre-lingual and post-lingual patients [12, 33].

\section{Conclusion}

Cochlear implantation, in which the auditory nerve is directly stimulated by means of electrodes placed in the cochlea, is a significantly useful method for the development of hearing skills and the emergence of a language and speech close to normal in patients with severe hearing loss.

Funding: The author(s) received no financial support for the research, authorship, and/or publication of this article.

Conflict of Interest: The authors declare that they have no conflict of interest.

Ethical statement: Since this research is a review study, no ethics committee decision was required. 


\section{Open Access Statement}

This is an open access journal which means that all content is freely available without charge to the user or his/her institution under the terms of the Creative Commons Attribution NonCommercial License

(http://creativecommons.org/licenses/bync/4.0). Users are allowed to read, download, copy, distribute, print, search, or link to the full texts of the articles, without asking prior permission from the publisher or the author.

Copyright (c) 2021: Author (s).

\section{References}

[1] Wilson BS, Tucci DL, Merson MH, et al. Global hearing health care: new findings and perspectives. Lancet. 2017;390(10111):2503-15.

[2] Organization WH. Addressing the rising prevalence of hearing loss. 2018, https://apps.who.int/iris/handle/10665/2603 36. Access date: 10.05.2021

[3] Clark JG. Uses and abuses of hearing loss classification. Asha. 1981;23(7):493-500.

[4] Davis AC, Hoffman HJ. Hearing loss: rising prevalence and impact. Bull World Health Organ. 2019;97(10):646-A.

[5] Tomblin JB, Harrison M, Ambrose SE, et al. Language outcomes in young children with mild to severe hearing loss. Ear Hear. 2015;36(0 1):76S-91S.

[6] Qi S, Mitchell RE. Large-scale academic achievement testing of deaf and hard-ofhearing students: Past, present, and future. J Deaf Stud Deaf Educ. 2012;17(1):1-18.

[7] Lederberg AR, Schick B, Spencer PE. Language and literacy development of deaf and hard-of-hearing children: successes and challenges. Dev Psychol. 2013;49(1):15-30.

[8] Roland L, Fischer C, Tran K, et al. Quality of life in children with hearing impairment: systematic review and meta-analysis. Otolaryngol Head Neck Surg. 2016;155(2):208-19.

[9] Emmett SD, Francis HW. The socioeconomic impact of hearing loss in US adults. Otol Neurotol. 2015;36(3):545-50.

[10] Mick P, Kawachi I, Lin FR. The association between hearing loss and social isolation in older adults. Otolaryngol Head Neck Surg. 2014;150(3):378-84.

[11]Ciorba A, Bianchini C, Pelucchi S, et al. The impact of hearing loss on the quality of life of elderly adults. Clin Interv Aging. 2012; 7:159-63.

[12]P. Ashley Wackym AT. Cochlear Implantation: Patient Evaluation and Device Selection. In: Krause C, editor. Cummings Otolaryngology Head and Neck Surgery. 6: Elsevier; 2015. p. 2428-50.

[13] Carlson ML, Driscoll CL, Gifford RH, et al. Cochlear implantation: current and future device options. Otolaryngol Clin North Am. 2012;45(1):221-48.

[14]Roche JP, Hansen MR. On the horizon: cochlear implant technology. Otolaryngol Clin North Am. 2015;48(6):1097-116. d

[15]Ramsden RT. History of cochlear implantation. Cochlear implants Int. 2013;14(sup4):3-5.

[16]Eshraghi AA, Nazarian R, Telischi FF, et al. The cochlear implant: historical aspects and future prospects. Anat Rec (Hoboken). 2012;295(11):1967-80.

[17] Wever EG, Bray CW. The nature of acoustic response: The relation between sound frequency and frequency of impulses in the auditory nerve. Journal of experimental psychology. 1930;13(5):373.

[18]AA, Gupta C, Ozdamar O, et al. Biomedical engineering principles of modern cochlear implants and recent surgical innovations. The Anatomical Record: Advances in 
Integrative Anatomy and Evolutionary Biology. 2012;295(11):1957-66.

[19]Kiang NY, Moxon EC. Physiological considerations in artificial stimulation of the inner ear. Ann Otol Rhinol Laryngol. 1972;81(5):714-30.

[20]Bilger R, Black F. Auditory prostheses in perspective. Ann Otol Rhinol Laryngol Suppl. 1977;86(3_suppl):3-10.

[21] Clark GM, Tong YC, Martin LF. A multiplechannel cochlear implant: An evaluation using open-set cid sentences. Laryngoscope. 1981;91(4):628-34.

[22]Naples JG, Ruckenstein MJ. Cochlear implant. Otolaryngol Clin North Am. 2020;53(1):87-102.

[23] Gelfand SA. Hearing: An introduction to psychological and physiological acoustics, sixth edition. CRC Press; 2018.

[24] Vincenti V, Bacciu A, Guida M, et al. Pediatric cochlear implantation: an update. Ital J Pediatr. 2014;40(1):1-7.

[25] Schramm D. Canadian position statement on bilateral cochlear implantation. J Otolaryngol Head Neck Surg. 2010;39(5):479-85.

[26] Steven Colburn H, Shinn-Cunningham B, Kidd J, et al. The perceptual consequences of binaural hearing. Int $\mathrm{J}$ Audiol. 2006;45(sup1):34-44.

[27] Yawn RJ, Rivas AC. Hearing Preservation Cochlear Implantation. In: David $\mathrm{S}$ Haynes, Rene H Gifford, George B Wanna, Alejandro C Rivas, editors. Cochlear Implants: From Principles to Practice. 1: JP Medical; 2020. p. 83-8

[28] Ontario HQ. Bilateral cochlear implantation: a health technology assessment. Ont Health Technol Assess Ser. 2018;18(6):1-139.

[29] Gordon K, Jiwani S, Papsin B. What is the optimal timing for bilateral cochlear implantation in children? Cochlear Implants Int. 2011;12(sup2):S14-S8.

[30]Litovsky RY, Gordon K. Bilateral cochlear implants in children: Effects of auditory experience and deprivation on auditory perception. Hear Res. 2016;338:76-87.

[31] Jiwani S, Papsin BC, Gordon KA. Early unilateral cochlear implantation promotes mature cortical asymmetries in adolescents who are deaf. Hum Brain Mapp. 2016;37(1):135-52.

[32] Firszt JB, Holden LK, Skinner MW, et al. Recognition of speech presented at soft to loud levels by adult cochlear implant recipients of three cochlear implant systems. Ear Hear. 2004;25(4):375-87.

[33]Russell JL, Pine HS, Young DL. Pediatric cochlear implantation: expanding applications and outcomes. Pediatr Clin North Am. 2013;60(4):841-63. 